\title{
REFLECTION
}

\section{One Last Question: Opening Pandora's Box?}

Janet M. Townsend, MD

Department of Family and Social Medicine, Montefiore Medical Center, Albert Einstein College of Medicine, Bronx, New York

Conflict of interest: none reported

\section{CORRESPONDING AUTHOR}

Janet $M$. Townsend, MD

Department of Family Medicine and Community Health

Commonwealth Medical College

501 Madison Ave

Scranton, PA 18510

jtownsend@tcmedc.org

\begin{abstract}
Family physicians are oriented and trained to inquire about the meaning of patients' symptoms and to recognize when major concerns or worry are present. Yet, in the context of busy practices and the many interruptions of our workday, we may concentrate too much on efficiency in conducting visits and completing tasks for patients, with a resulting narrow focus on the medical or biological aspects of the patient's complaint. This essay tells the story of 2 patient encounters in which I, an experienced family physician, almost missed noticing deep fears experienced by each patient. These experiences led me to reflect on the contextual, patient, and personal factors that can get in the way of recognizing and reaching a deeper understanding of patients' worries, and on the power we have to assuage fears when we address them directly instead of hesitating to open Pandora's box.
\end{abstract}

Ann Fam Med 2009;7:176-178. DOI: 10.1370/afm.948.

I $\mathrm{t}$ had been a typical Monday morning at the teaching practice where I see patients, though patient flow was chaotic as we implemented a new registration system. I was running a few patients behind and regretting that my patients had to wait so long. Mrs B was next. I had assumed her care several months before. A 70-year old retired licensed practical nurse with diabetes, hypertension, and recent leg edema, Mrs B always seemed well-informed and on top of things.

This time I was concerned because her serum creatinine had risen far above her baseline. I informed her, and she seemed surprised that there would be any problem with her kidneys, even though her creatinine had hovered around $1.3 \mathrm{mg} / \mathrm{dL}$ for several years. Her previous physician had ordered a renal sonogram last year, which she had understood to be normal. We discussed, in a matter-of-fact way, the possible causes of the decline in kidney function and decided to repeat the laboratory tests and a urinalysis. We also anticipated what would be involved in further work-up if the laboratory results confirmed the change in her creatinine level.

I shuffled papers in the chart to review any previous evaluation and her medication list, struggled with a new laboratory requisition sheet, and checked on her routine monitoring for diabetes and last mammogram. I was already past the 15 minutes allotted for her visit. Mrs B answered all my questions clearly and confidently. Just as I was about to hand Mrs B the laboratory orders and appointment slip and pick up the chart to leave, I stopped, put everything down, and looked her in the eye.

"Mrs B, I rushed so much to take care of everything today-we talked about the kidney problem rather quickly. How are you feeling about all this?"

"Scared to death, Doctor, scared to death," she said, without blinking an eye. "Everyone in my family has kidney trouble-my mother, my uncle. I have 2 sisters on dialysis." Her eyes filled with tears.

"Then you've been dreading this?" I asked.

What was it that made me pause to ask that key question about how she was feeling? I had been close to walking out the door without grasp- 
ing how worried she was. Yet I did pause, for those few seconds of silence, to look once more at the patient, to connect. We took a few more minutes to talk about her fears. I assured her that I would let her know the results promptly, and that I anticipated an early consultation with a nephrologist. She left the office looking somewhat relieved, expecting to wait several days for the results.

Later that week, I returned to the office for some patient follow-up and chart review. One of our medical assistants asked me to handle an authorization and referral for a vacationing colleague. It was for an ultrasoundguided breast biopsy for a patient whose mammogram revealed a lesion. The patient was a 68 -year-old woman in good health who I didn't know. Not wanting to write the referral without checking with the patient, I called her at home and had the following conversation.

"Hello, Mrs M, this is Dr Townsend. I work with Dr $\mathrm{P}$, who is on vacation. I understand you had to go back to the hospital to get some other x-rays of your breast."

"Yes, Doctor," she said, a Caribbean lilt in her voice.

"Did they tell you they had seen a spot, a lump that needs a biopsy?"

"Yes, Doctor."

"Did they schedule the biopsy?"

"Yes, Doctor, next Tuesday."

"Is that $\mathrm{OK}$ with you? Do you understand what they are going to do?"

"Yes, Doctor."

"And you'll be able to go?"

"Yes, Doctor."

"I'll write the referral for Dr P and everything will be set."

"Yes, Doctor."

"And I'll tell Dr. P when he gets back."

"Yes, Doctor."

After a brief silence, I was about to say good-bye when I asked one more question, perhaps in hopes of getting an answer beyond the deferential, "Yes, Doctor".

"Mrs M, are you worried about this?"

"Oh, yes, Doctor", a near-sob in her voice.

"You're worried you have cancer?"

"Yes, Doctor."

"Have you told anyone about this?

"No, Doctor."

We talked for a few more minutes, about how mammograms help us find cancers early and whether she could talk to a family member or friend about her worries. She promised to talk about it with her daughter, and I promised to call the radiologist to learn more about what they saw on her mammogram. I urged her not to worry alone. Later on that day, I called Mrs M to let her know that the radiologist said the lesion was very small.
In our busy practice lives, we can easily miss the worry beneath the surface of our conversations with patients. As a family doctor, confident of my skills in integrating inquiry about psychosocial issues in routine care and committed to training young physicians in this model, I was surprised that I had come close to ignoring this key dimension in these 2 encounters. Had I been misled by the competence of Mrs B or the reserve of Mrs M? Had my use of closed-ended questions, seemingly appropriate for a simple telephone call or for discussing laboratory results, limited what the patients could tell me? Was I distracted by the confusion and delays in the practice that first day, or was I simply hurrying because I was running behind? Did my intention to make a brief stop at the practice to do "just a few things" limit my openness to clues from Mrs M?

Yet I did pause to ask the one last question, the one that allowed these patients to reveal their worry. A psychologist colleague always reminds us that including just one question on the psychosocial dimension in every visit is likely to pay off. I've found her advice to be true over the years. Even when hurried and hassled, the visit feels incomplete without making room for that final check-in with the patient about the meaning or impact of what we've said. Silence, pauses, eye contact, a last question - these ingrained habits serve as a check on a premature end to the visit and assure a connection with the patient.

We often worry that such questions will open Pandora's box, the one opened by that much-maligned goddess who, in Greek mythology, unleashed all the ills of the world. Truly, we physicians are messengers of Pandora's problem-filled world. We connect patients to that world, almost as immediately as aches and pains do. In a way it is our job to open Pandora's box-we question, we probe, we order tests, we name risks, we raise issues patients would just as soon leave alone. We play Pandora. We connect patients to their illness. We can't avoid it. It's what we do.

Yet our curiosity and our questions can lead to insights into the patient's world that help us to share worry and isolation or to mobilize support from family and friends. In this regard, it is interesting to recall that after Pandora opened her box, letting loose all that chaos, she managed to shut it just in time to prevent hope from escaping. As physicians, by connecting to patients through simple personal questions, we connect them to hope. In small ways, our attention to patients' unspoken fears helps to maintain that emotional quality, hope, so essential to well-being. And hope springs not only from positive prognoses and reassurance that we may be able to offer, but also from the power of patients' own reflections, their ability to name fears 
and to solve problems, and their willingness to ask for help from others. In Greek, after all, Pandora means "all gifts." We, too, are endowed with gifts as a result of our training, the diagnostic tools and treatment options at our disposal, an ever-expanding medical and scientific knowledge, and the wisdom gained through experience, which we offer to patients. By opening Pandora's box, we make room for listening, for reflection, and for putting things into perspective, and with our gifts, we open doors for healing.

We should embrace Pandora's curiosity and her courage. Perhaps we need not fear opening Pandora's box, but rather we should fear leaving it shut.

$$
* * * * * * * *
$$

I want to offer a final note, having just returned from a gathering of the leaders of our discipline at the Association of Departments of Family Medicine winter meeting. I believe this moment is precious and unique in medicine, when mounting evidence documents the value of family medicine and primary care in keeping people healthy and in reducing mortality. We will have many new tools at our fingertips in the coming decades, including medications tailored to individual genetic patterns, ever more amazing imaging techniques, and less-invasive approaches to surgery. Yet, the processes of care upon which family medicine is built and the relationships that ensue may be our most powerful tool of all. As my new Dean* notes, "Listening is the cornerstone of medicine."

Let us raise our collective voice in support of a system of care that makes room for listening - to patients, to each other, and to communities.

To read or post commentaries in response to this article, see it online at http://www.annfammed.org/cgi/content/full/7/2/176.

Key words: Primary health care; psychosocial issues in health care; patient-physician relations

Submitted May 23, 2008; submitted, revised, September 4, 2008; accepted September 15, 2008.

Acknowledgments: I wish to acknowledge Henry Geisinger, MS, for his interpretation of Pandora's story and his contribution to the framework of this essay, and Darwin Deen, MD, Paul Gross, MD, Rose Guilbe, MD, and Eliana Korin, DiplPsic, for their helpful comments and insights. I am grateful for those who shared family medicine's gifts with me and showed me the path to becoming the physician I could be. Among the many teachers and colleagues who taught me how to listen are Lucy Candib, Herb Fendley, Joanna Shapiro, Carl Meier, Barbara Franzblau, Hal Strelnick, Eliana Korin, and Chinita Fulchon.

*Bob D'Alessandri, MD, President and Founding Dean, The Commonwealth Medical College, Scranton, Pennsylvania. 